\title{
Del conflicto al posacuerdo: actualidad constitucional de la doctrina de la seguridad nacional ante la justicia transicional
}

\author{
Hernán Alejandro Olano-García*
}

\footnotetext{
Doctor magna cum laude en Derecho Canónico. Director del programa de Humanidades y director del departamento de Historia y Estudios Socioculturales, Universidad de La Sabana, Bogotá, Colombia.

Correo electrónico:

hernan.olano@unisabana.edu.co
}

Recibido: 3 de noviembre del 2015 Aprobado: 19 de enero del 2016

Cómo citar este artículo: Hernán Alejandro Olano-García. Del conflicto al posacuerdo, actualidad constitucional de la doctrina de la seguridad nacional ante la justicia transicional. DIXI 23. Abril 2016. Pág. 9. doi: http://dx.doi.org/10.16925/ di.v18i23.1288

\section{Resumen}

Propósito: el presente artículo de reflexión realiza un recorrido por las diferentes épocas de la violencia en Colombia, al presentar un análisis para el posconflicto y revisar algunos aspectos de la doctrina de la seguridad nacional, a fin de ser aplicados dentro de la desmovilización y el posconflicto en concordancia con la justicia transicional. Descripción: dentro de la línea de investigación en historia de las instituciones, el autor describe las etapas y causas de la violencia en Colombia, ya que esta adopta un carácter de preocupación sudamericana por cuanto los países limítrofes se ven afectados por los problemas que el propio conflicto les acarrea. Punto de vista: aunque las fórmulas de transición hacia la paz ya han sido dadas por la historia, se expresa que, en lo jurídico, el Tratado de Roma no ha reemplazado la jurisdicción penal ordinaria nacional ni la denominada justicia transicional y que, como paso firme hacia la paz, los acuerdos deberían incluir que las investigaciones o los enjuiciamientos se realicen conforme al derecho nacional y a los derechos constitucionales fundamentales por él protegidos. Conclusiones: la nueva justicia transicional puede generar conflictos de competencia con las Altas Cortes, pues el nuevo Tribunal de Paz, con presencia de jueces internacionales, será el nuevo organismo de cierre judicial en Colombia.

Palabras clave: conflicto, derechos humanos, derecho internacional humanitario, desescalamiento, posacuerdos, posconflicto. 


\title{
From Conflict to the Post-Peace Agreement: Current Constitutional Affairs of the National Security Doctrine regarding Transitional Justice
}

\begin{abstract}
Purpose: this reflection article outlines the different periods of violence in Colombia by presenting an analysis for post-conflict and reviewing some aspects of the national security doctrine to be applied in the context of demobilization and post-conflict according to transitional justice. Description: within the line of research into the history of institutions, the stages and causes of violence in Colombia are described since it has become a South American concern as bordering countries are affected by the problems derived from the conflict itself. Point of view: while formulas of transition to peace have already been given by history, it is expressed that, from a legal perspective, the Treaty of Rome has not replaced the national ordinary criminal jurisdiction or the so-called transitional justice and that, as a firm step towards peace, agreements should include that investigations or trials are carried out in accordance with the national law and the fundamental constitutional rights protected by it. Conclusions: the new transitional justice may cause conflicts of power with High Courts since the new Peace Tribunal, with the presence of international judges, will be the new judicial closure body in Colombia.
\end{abstract}

Keywords: conflict, human rights, international humanitarian law, de-escalation, post-peace agreements, post-conflict.

\section{Do conflito ao pós-acordo: atualidade constitucional da doutrina da segurança nacional diante da justiça transicional}

\section{Resumo}

Propósito: o presente artigo de reflexão percorre pelas diferentes épocas da violência na Colômbia, ao apresentar uma análise para o pós-conflito e revisar alguns aspectos da doutrina da segurança nacional, a fim de serem aplicados dentro da desmobilização e do pós-conflito em concordância com a justiça transicional. Descrição: dentro da linha de pesquisa em história das instituições, descrevem-se as etapas e as causas da violência na Colômbia, uma vez que esta adota um caráter de preocupação sul-americana por quanto os países limítrofes se veem afetados pelos problemas que o próprio conflito acarreta. Ponto de vista: ainda que as fórmulas de transição para a paz já tenham sido dadas pela história, expressa-se que, no jurídico, o Tratado de Roma não substituiu a jurisdição penal ordinária nacional nem a denominada justiça transicional e que, como passo firme em direção à paz, os acordos deveriam incluir que as pesquisas ou os processos se realizem conforme o direito nacional e os direitos constitucionais fundamentais por ele protegidos. Conclusões: a nova justiça transicional pode gerar conflitos de competencias com as Altas Cortes, pois o novo Tribunal de Paz, com presença de juízes internacionais, será o novo organismo de encerramento judicial na Colômbia.

Palavras-chave: conflito, direitos humanos, direito internacional humanitário, desescalada, pós-acordos, pós-conflito. 


\section{INTRODUCCIÓN ${ }^{1}$}

Dentro de la línea de investigación en historia de las instituciones, con el presente artículo de revisión se busca hacer un recorrido por las diferentes épocas de la violencia en Colombia. Se revisarán algunos aspectos de la doctrina de la seguridad nacional, de manera que sean aplicados dentro de la desmovilización y el posconflicto en concordancia con la justicia transicional, ya que al lado de muchos episodios de la historia colombiana la violencia generalizada siempre ha estado presente. Por tanto, se presenta esta visión particular, basada en un método simple, en los datos y los acontecimientos, así como en la observación personal de diversos episodios de la vida social del país.

La explicación del conflicto en Colombia es un asunto complejo. Sus causas son múltiples y su finalización es casi impredecible, en razón a la lucha continua por el poder. La ruptura del orden jurídico iniciada por acción de los violentos y la necesidad de proteger a la sociedad han llevado, en muchos casos, al aumento de la criminalidad, fruto de una violencia predominante desde mucho tiempo atrás, originada en un sectarismo ancestral que mantiene al país en una situación de "turbulencia" política.

La violencia permea la vida colombiana, todo aquello que Jorge Eliécer Gaitán denominó "el país nacional y el país político":

En Colombia hay dos países: el país político que piensa en sus empleos, en su mecánica y en su poder, y el país nacional que piensa en su trabajo, en su salud, en su cultura, desatendidos por el país político. ¡Tremendo drama en la historia de un pueblo!

El proyecto de investigación sobre el cual se desarrolló este artículo de revisión gira en torno a dos grandes problemas:

El primero de ellos es el concerniente a los puntos de coincidencia y divergencia de los estándares de justificación racional utilizados en el Derecho Internacional (especialmente en el contexto interamericano) y en las diversas jurisdicciones locales. El segundo, más crítico y valorativo, tiene que ver con la efectiva adecuación de la jurisprudencia local (especialmente en

1. El presente artículo forma parte del proyecto de investigación "Historia de las Instituciones-I", el cual se desarrolla en la Universidad de La Sabana, institución que lo financia.

2. Véase Herbert Braun. Mataron a Gaitán. Vida PÚBlica y Violencia urbana en Colombia. Alfaguara. (2013). Pág. 290. materia de Derechos Humanos) a los estándares internacionales de racionalidad de los fallos judiciales. ${ }^{3}$

Estos dos problemas, a su vez, se pueden subsumir dentro del macroproblema de las relaciones del Derecho internacional y los ordenamientos jurídicos locales, en torno a la utilización de un buen número de términos, los cuales serán de uso frecuente tan pronto se presente en Colombia la finalización del conflicto.

En el artículo 205 de la Ley 1448 de 2011,4 el Congreso de la República le concedió al Presidente de la República precisas facultades extraordinarias por el término de seis meses para expedir la regulación de derechos y garantías de las víctimas pertenecientes a pueblos indígenas, comunidades Rom (gitanos) y comunidades negras (afrocolombianas, raizales y palenqueras). Así, entonces, se enriqueció el marco normativo e institucional de la atención, asistencia y reparación integral de las víctimas pertenecientes a estos grupos étnicos minoritarios en Colombia, que se sumaron a la Ley 288 de 1996 y a las vulneraciones ocurridas a partir del 1 de diciembre de 1985 en el marco del conflicto armado interno.

En la Sentencia C-328 de 1996, la Corte Constitucional de Colombia advirtió:

El estado de anormalidad institucional, concebido con carácter excepcional, no puede tornarse permanente. Para la Constitución Política, sólo es de recibo una situación de anormalidad excepcional y no permanente. La utilización casi ininterrumpida de los poderes excepcionales no parece resolver la crisis que sufre el país. ${ }^{5}$

\section{DESARROLLO}

Fue John Kenneth Galbraith ${ }^{6}$ quien definió la era contemporánea como una de incertidumbre. En este momento, desde el 11 de septiembre de 2001, el mundo pasa por un proceso de cambios acelerados y

\footnotetext{
3. Id.

4. Véase Ley 1448 de 2011. Por la cual se dictan medidas de atención, asistencia y reparación integral a las víctimas del conflicto armado interno y se dictan otras disposiciones. Junio 10 de 2011. Do N. ${ }^{\circ} 48096$.

5. Véase Corte Constitucional de Colombia. Sentencia C-328/96 (M.P. Eduardo Cifuentes Muñoz; Julio 25 de 1996).

6. Véase John K. Galbraith. LA ERA DE LA INCERTIDUMBre. Universidad de Brasilia. (1979). Pág. 379.
} 
profundos en materia de seguridad y defensa, los cuales hoy en día forman parte de las principales preocupaciones de los dirigentes, y las sociedades habrán de comprender día a día esa realidad. La mayor garantía para la paz es la existencia de un poder nacional equilibrado, cuyo componente militar sea capaz de contribuir efectivamente a solucionar los problemas de seguridad, y sea eficaz al asegurar la defensa del país contra agresiones internas y externas.

La comunidad internacional ha venido expresando y demostrando interés en acompañar y contribuir al proceso de reconciliación en Colombia, en diferentes modalidades. Sin embargo, no obstante la ayuda desinteresada de múltiples observadores en el proceso de paz y reconciliación nacional en nuestro país, ya se verá cómo no es verdad que los tratados internacionales suscritos por Colombia prohíban a su población organizarse con el propósito de protegerse de los delincuentes y la obliguen a comportarse como un espectador pasivo de su propia destrucción. Por ahora baste decir, a fin de rechazar esa tesis, lo siguiente: es evidente que ninguna norma del Derecho Internacional Humanitario prohíbe a los habitantes de un Estado, en el cual hay un conflicto interno, pagar los impuestos y las contribuciones que las leyes les imponen. Esos impuestos, indudablemente, hacen posible que el Estado cumpla sus fines, comenzando por el primordial de "mantener el orden público y proteger la vida, la honra y los bienes de las personas".

Sin embargo, esto equivale a afirmar que cualquier crisis política que no pueda solucionarse por los medios ordinarios no implica el desahucio de nuestra Constitución, sino la aceptación de las reglas y los tratados del Derecho Internacional Humanitario como el único límite absolutamente infranqueable por el Estado. No obstante, en el caso de Colombia, la Constitución contiene una referencia expresa a la realidad de los tratados que limitan las posibilidades de ese Estado, la cual transfiere ciertas competencias que adoptan una concepción más flexible y más adecuada a los tiempos que corren, así como protegen el núcleo de la libertad estatal propio de la autodeterminación, sin que ello implique un desconocimiento de reglas y de principios de aceptación universal.

El conflicto colombiano adopta un carácter de preocupación sudamericana solo cuando los países limítrofes se ven afectados por problemas que el conflicto mismo ocasiona en sus propios territorios (desplazados, delincuencia, tráfico de drogas, etc.).

Resulta pertinente hacer una referencia al Barón de Montesquieu, para quien la libertad no existe más que en un gobierno moderado, pero esta condición no es suficiente si, por alguna circunstancia, ese mismo gobierno abusa del poder.

Una experiencia eterna -dice- nos enseña que todo hombre que detenta el poder es llevado a abusar de él, y, por este camino, va hasta donde encuentra límites adecuados para su contención. ¿Quién lo creería? La virtud misma tiene necesidad de límites. El abuso del poder no es impedido sino en el instante en que por disposición misma de las cosas el poder detenga al poder, lo cual implica no un poder único y concentrado, sino una cierta distribución de poderes separados. $^{7}$

Este es el mérito más significativo de Montesquieu: haber analizado, con mayor claridad que Locke, la separación de los poderes, que distingue en poder legislativo, ejecutivo y judicial, explicando cómo, dado que esos poderes se hacen contrapeso mutuo, la naturaleza misma de las cosas los llevará a obrar en pleno concierto y armonía. Este concepto indica que lo más importante para el autor mencionado no era tanto la separación de los poderes, cuanto la mutua colaboración entre ellos en el propósito de alcanzar los fines naturales del Estado.

Cabe citar en este punto al doctor Vladimiro Naranjo Mesa, que expresa:

La doctrina clásica de la soberanía del Estado consiste fundamentalmente en el supuesto de que en toda sociedad existe un poder absoluto, superior e incontrolado, que tiene la decisión final con respecto a la adopción y promulgación de las normas jurídicas que deben regir esa sociedad. Según esta concepción, el soberano no está sujeto a ninguna autoridad superior y puede emplear - de manera limitada - la coacción sobre quienes están sometidos a su poder. El derecho puede estar así encarnado en una persona, como ocurría en una monarquía absoluta o en un régimen autoritario; en una pluralidad de personas, como en las monarquías limitadas o en la aristocracia, o en todo el conglomerado de la población como ocurre en las democracias. ${ }^{8}$

$\mathrm{Y}$ es esto específicamente lo que ocurre en Colombia, tal como se deriva de la lectura del artículo 3 de la Constitución Política.

\footnotetext{
7. Véase Hernán A. Olano. Constitución Política de Colombia. Doctrina y Ley. (2002). Pág. 44.

8. Véase Vladimiro Naranjo. Elementos de Teoría Constitucional
} E Instituciones Políticas. Temis. (1997). Pág. 43. 
Se considera actualmente que los cuatro Convenios de Ginebra de 1949, así como sus dos protocolos adicionales de 1977, son los principales instrumentos del Derecho Internacional Humanitario (DIH). Al respecto, cabe señalar que en los protocolos de 1977 se incluye, en gran parte, el Derecho de La Haya, en el cual se utilizan muchos de los términos aquí incluidos.

El tema de los derechos humanos ha cobrado especial importancia desde la expedición de la Carta de 1991. La arbitrariedad y la violencia ya lo habían situado como un tema prioritario dentro del procedimiento de reforma, a fin de incluir en el ordenamiento del país las consideraciones de los convenios internacionales, las cuales integran elementos de juicio valiosos para desarrollar la Carta de Derechos y los distintos mecanismos de protección que aquí se analizarán.

La fuerza de los derechos humanos a nivel internacional es cada vez más grande. La Corte Europea de Derechos Humanos y la Corte Interamericana de Derechos Humanos han adoptado decisiones trascendentales sobre el tema, que han llegado inclusive a desencadenar procesos de reforma constitucional en otras latitudes. Y en un plano más político, pero menos significativo, el Consejo de Seguridad de las Naciones Unidas resolvió formalmente justificar limitaciones a la soberanía de un Estado con base en la defensa de los derechos humanos, como sucedió con los kurdos en Irán. Se está desarrollando, entonces, un campo inmensamente rico que ha llevado a un replanteamiento de doctrinas jurídicas y posiciones políticas que tenían una larga tradición. No es este el lugar apropiado para profundizar en este y otros temas relativos a la interpretación de los derechos y sus implicaciones. De lo que se trata simplemente es de recoger fuentes normativas indispensables para entender los alcances de la Carta de Derechos. ${ }^{9}$

La Constitución de 1991 desarrolla y garantiza la defensa y el respeto de los derechos humanos. Más de diez artículos de nuestra Carta Fundamental hacen mención a la necesidad de formar, respetar y divulgarlos. Se destacan particularmente los artículos 1, 2, 3, 85 y 95, los cuales determinan los principios fundamentales de la organización política y administrativa del Estado, caracterizada por: la descentralización, la

9. Véase Manuel J. Cepeda. Los Derechos Constitucionales, FUENTES INTERNACIONALES PARA SU INTERPRETACIÓN. Presidencia de la República de Colombia. (1994). Pág. 27. participación y el respeto a la dignidad humana; la promoción y el respeto de los derechos humanos dentro de un orden justo; la preeminencia del constituyente primario en la orientación de los destinos del Estado; y la obligatoriedad inmediata de la aplicación de los derechos humanos en el país, todo lo anterior fundamentado en el ejercicio pleno de la ciudadanía.

La vigencia y el respeto de los derechos humanos no es solo un mandato constitucional, sino también una condición indispensable para que los colombianos se consideren una sociedad civilizada. Como mandato, la defensa de los derechos humanos es una responsabilidad individual, social e institucional que se sustenta, en últimas, en la apropiación por parte de todos los colombianos y sus instituciones de una nueva cultura de derechos humanos.

Las autoridades territoriales, dado el anterior contexto, deben estar en capacidad de desarrollar actividades regionales a favor de la promoción, el ejercicio y la divulgación de los derechos humanos en su jurisdicción. Igualmente, se pueden crear o fortalecer los fondos y las instancias de atención a los desplazados; diseñar y ejecutar programas de asistencia de emergencia para los dirigentes políticos y sociales, los empleados públicos y las comunidades en general cuya vida e integridad física se encuentren en alto riesgo; así como construir y adecuar albergues provisionales en los casos específicos de los desplazados por la violencia.

La Constitución Política de Colombia de 1991, en sus artículos 81 y 223, reserva al Gobierno la facultad de introducir y fabricar armas, municiones de guerra y explosivos, pero la acompaña de un mandato perentorio que traslada a aquel el manejo de la situación: "Nadie podrá poseerlos ni portarlos sin permiso de la autoridad competente". ${ }^{10}$

La norma del artículo 223, como puede verse claramente, tiene la doble función de prohibir de manera general el porte o la posesión de armas, municiones de guerra y explosivos, así como la de facultar a la autoridad competente para otorgar permisos que faciliten tanto la actividad armada de los organismos nacionales de seguridad (porque bajo la prohibición absoluta inicial estos tampoco podrían armarse), como de los particulares en casos especiales.

Por lo demás, se fija en la ley la potestad de reglamentar lo relativo al porte de armas, que es la manera de mantener el monopolio de las armas en manos del Estado y de garantizarle su poder coercitivo a la ley

\footnotetext{
10. Véase Constitución Política de Colombia [Const]. Arts. 81 y 223. Julio 7 de 1991 (Colombia).
} 
en procura de su efectividad, así como de las decisiones administrativas.

Existe consciencia de que a los diferentes grupos de la delincuencia organizada se atribuyen, entre otros, los siguientes hechos reseñados por la Corte Constitucional en la Sentencia C-328 de 1996: ${ }^{11}$

1. Adquisición ilícita de material de guerra.

2. Amedrentamiento de la población rural y urbana, y aprovechamiento de esa condición para sus propósitos delictivos.

3. Amenazas y acciones contra la vida, la integridad personal y la libertad de personalidades públicas, con el objeto de ejercer influencia política y desestabilizar a las instituciones.

4. Aumento del control territorial y consiguiente desprotección de los ciudadanos sujetos a su directa influencia.

5. Destrucción sistemática de la infraestructura productiva del país.

6. Expansión de los frentes armados y de sus zonas de influencia.

7. Incremento progresivo de las fuentes financieras que se nutren de las actividades ilícitas, como los secuestros y las extorsiones, y el fruto del narcotráfico y la desviación de fondos públicos.

8. Infiltración en las administraciones locales y aplicación de prácticas coercitivas contra sus funcionarios.

9. Obstaculización simultánea de importantes vías terrestres y cierre temporal de algunas de ellas.

10. Producción y venta de sustancias psicotrópicas.

11. Tomas de municipios y asaltos a puestos de Policía.

La mayoría de los hechos mencionados reviste carácter endémico, y por lo tanto, su mera ocurrencia no justificaría constitucionalmente la intervención del Presidente de la República, sino de los propios alcaldes, ya que por tratarse de situaciones que forman parte de la violencia crónica que afecta al país, para enfrentarlas no puede acudirse a medidas de excepción, cuya función es la de repeler hechos sobrevinientes que afecten de manera excepcional la estabilidad del orden constitucional. Si interviniera la creación de una zona de distensión, lo único que ocurriría es que se estaría justificando la ineficiencia del Estado para diseñar mecanismos definitivos de solución de las diversas manifestaciones de violencia, so pretexto de la utilización de medidas cuya vigencia compromete el normal funcionamiento de las ramas del poder público, y el goce de los derechos y las

11. Véase Corte Constitucional de Colombia, supra, nota 5. libertades que integran el núcleo básico de un Estado democrático de derecho.

Sin embargo, se sabe que son los alcaldes municipales los que tienen la misión de restringir el uso de armas en su territorio. Sobre el particular, la Corte Constitucional se pronunció:

Es natural que los Estados con el fin de mantener condiciones mínimas de convivencia se reserven el derecho de restringir el acceso y el uso de las armas de defensa personal y las municiones, debido al potencial efectivo que éstas tienen. Es pues perfectamente legítimo que el Estado someta su fabricación, comercio o porte a permisos previos, ya que de esa manera el Estado regula el uso legítimo de la coacción. ${ }^{12}$

Conviene destacar que el monopolio es la exclusividad de una determinada comercialización y que esta, respecto a las armas, así como su posesión y porte están deferidos a la reglamentación legal.

A estas consideraciones, la Corte Constitucional en la Sentencia C-572 de 1997, de los magistrados Jorge Arango Mejía y Alejandro Martínez Caballero, añade lo siguiente:

Es verdad que en una sociedad ideal, nadie, ni siquiera los agentes del Estado, deberían tener y portar armas: la fuerza no tendría que utilizarse, porque las normas, todas las normas, se cumplirían espontáneamente por los obligados a su observancia; y nadie tendría que ejercer la legítima defensa, porque no habría agresión ni amenaza. Ese Estado ideal, sin embargo, jamás se alcanzará mientras la Tierra exista y esté poblada por la especie humana. ${ }^{13}$

Lo dice la Corte Constitucional, en la Sentencia anteriormente citada: "la seguridad es un servicio público primario". Así, la seguridad de la sociedad, como supuesto del orden, de la paz y del disfrute de los derechos, es un fin del Estado, al cual corresponde la misión que el inciso segundo del artículo 2 de la Constitución impone a las autoridades de la República: "De ninguno como de este servicio puede predicarse que es inherente a la finalidad social del Estado, para utilizar las mismas palabras del inciso primero del artículo 365 de la Constitución”. ${ }^{14}$

\footnotetext{
12. Véase Corte Constitucional de Colombia. Sentencia T-102/93. (M.P. Carlos Gaviria Díaz; Marzo 10 de 1993).

13. Véase Corte Constitucional de Colombia. Sentencia C-572 /97. (M.P. Jorge Arango Mejía y Alejandro Martínez Caballero; Noviembre 7 de 1997).

14. Id. Pág. 24
} 
Añade el alto tribunal una consideración muy importante, y es que como servicio público, la seguridad está sometida al régimen jurídico que la ley establezca y, también por serlo, puede ser prestada por el Estado, directa o indirectamente, por comunidades organizadas o por los particulares, como lo dispone el artículo 365 superior. Por eso, es la propia ley la que, al reglamentar este servicio, determina quién y cómo lo debe prestar a través de sus municipios, precisamente cuando el Estado se da cuenta de su ineficiencia o de su falta de capacidad para combatir el crimen organizado y de garantizar la vida, la honra, los bienes, las creencias y demás derechos de sus asociados. Esos son aspectos aún por organizar en la redacción de los acuerdos. El poder en el Estado de derecho, tal como lo dispone en clasificación previa André Hauriou, ${ }^{15}$ posee seis caracteres específicos:

a) Es un poder de superposición y centralización, lo cual supone la supresión de poderes políticos intermedios que afecten la autoridad del poder central sobre el grupo humano.

b) Es un poder político dado que es un poder de arbitraje, de manera que no es patrimonial y su obediencia está asegurada por sanciones que se imponen al individuo.

c) Es un poder civil, dado que lo organiza en la paz y el orden un grupo de ciudadanos que posee la representación del pueblo como titular de la soberanía.

d) Es un poder temporal que corresponde exclusivamente al Estado, separado del poder espiritual que corresponde a la Iglesia.

e) Es un poder monopolizador de la coerción material, dado que el Estado es el único que puede administrar justicia y poseer fuerzas armadas (sin embargo, en este punto se discrepa pues el Estado no posee la totalidad del monopolio de la fuerza en Colombia).

f) Es un poder soberano, lo cual significa que en el orden interno el poder del Estado se sobrepone a todos los otros que existan dentro de él, y a nivel internacional o externo, su poder se sitúa en un plano de igualdad con otros Estados.

En este orden de ideas, se podría afirmar que la referencia al artículo 2 constitucional ponía al Estado

15. André Hauriou. (1997). Citado en el capítulo v de: Carlos Alberto Olano Valderrama y Hernán Alejandro Olano García. Derecho Constitucional general E Instituciones Políticas - Estado Social de Derecho. 3. ${ }^{a}$ ed. Ediciones Librería del Profesional. (2000). Pág. 45. y a todas sus autoridades bajo la coordinación del presidente, en función de los objetivos de seguridad y defensa. Sin embargo, dentro del conjunto del Estado, la seguridad y la defensa nacionales no son objetivos en sí mismos, ni corresponden a metas divergentes a sus fines constitucionales. Son presupuestos para garantizar la efectividad de los principios, derechos y deberes constitucionales, y estos, según lo dispone el mismo artículo 2 superior, son fines propios del Estado.

En lo que tiene que ver con la protección de los valores fundamentales de un Estado social y democrático de Derecho, la Constitución introdujo un gran vuelco filosófico. La tarea de desentrañar el significado de estos valores no es fácil y será objeto del desarrollo del país. Tomará tiempo. A veces los criterios objetivos podrán parecer insuficientes. Por eso, la misma Carta le concede a los tratados internacionales sobre derechos humanos un valor especial y determina que no pueden ser desconocidos ni siquiera en los estados de excepción.

Con base en todos estos aspectos, se puede ver que las funciones del Estado están cambiando. Más que construir autoridad, lo que se persigue con este curso y estos planteamientos es fortalecer la legitimidad institucional, ampliar la democracia, abrir espacios para el pluralismo, promover la igualdad y encontrar las necesidades del país a fin de fortalecer la paz y la democracia.

Es muy importante también revisar otros conceptos como el de la justicia transicional, que supone el conjunto de medidas judiciales y políticas utilizado como reparación por las violaciones masivas de derechos humanos.

Su objetivo es reconocer a las víctimas y promover iniciativas de paz, reconciliación y democracia. La justicia transicional no es una forma especial de justicia, sino una justicia adaptada a sociedades que se transforman a sí mismas después de un período de violación generalizada de los derechos humanos. En algunos casos, estas transformaciones suceden de un momento a otro; en otros, pueden tener lugar después de mucho tiempo.

Los enfoques básicos para la justicia transicional constan de una serie de iniciativas, entre las cuales se encuentran las siguientes:

1. Acciones penales. Se trata de investigaciones judiciales de los responsables de violaciones de derechos humanos. A menudo, los fiscales hacen hincapié en las investigaciones de los sospechosos considerados responsables de crímenes masivos o sistemáticos. 
2. Comisiones de la verdad. Tienen como fin primordial investigar e informar sobre los abusos cometidos durante períodos clave del pasado reciente. Suele tratarse de órganos oficiales del Estado que formulan recomendaciones para remediar tales abusos y prevenir su repetición.

3. Iniciativas de conmemoración. Entre ellas figuran los museos y los monumentos públicos, que preservan la memoria de las víctimas y aumentan la conciencia moral sobre los abusos cometidos en el pasado, con el fin de construir un baluarte en contra de su repetición.

4. Justicia de género. Incluye esfuerzos para combatir la impunidad de la violencia sexual y de género, y para asegurar el acceso de las mujeres, en igualdad de condiciones, a los programas de reparación por violaciones a los derechos humanos.

5. Programas de reparación. Son iniciativas patrocinadas por el Estado que ayudan a la reparación material y moral de los daños causados por abusos del pasado. En general, consisten en una combinación de beneficios materiales y simbólicos para las víctimas, que pueden incluir desde compensaciones financieras hasta peticiones de perdón oficiales.

6. Reforma institucional. Busca transformar las Fuerzas Armadas, la Policía, el poder judicial y las instituciones estatales, con el fin de modificar instrumentos de represión y corrupción y convertirlos en herramientas íntegras de servicio público.

A nivel internacional, nuestro bloque de convencionalidad, como base jurídica de la justicia transicional, es la decisión de la Corte Interamericana de Derechos Humanos en 1988, en el caso Velásquez Rodríguez vs. Honduras. En este se determinó que todos los Estados tienen cuatro obligaciones fundamentales en el ámbito de los derechos humanos:

- Garantizar la reparación de las víctimas.

- Imponer las sanciones adecuadas a los responsables de las violaciones.

- Llevar a cabo investigaciones serias cuando se cometen violaciones.

- Tomar medidas razonables para prevenir violaciones de derechos humanos.

Asimismo, algunas de las medidas de satisfacción que la Corte Interamericana de Derechos Humanos (IDH) ha considerado - las cuales en ocasiones también se traducen en garantías de no repetición, con énfasis en las declaradas y comunes respecto al Estado colombiano- son las siguientes, cuyos términos también se han de tener presentes: ${ }^{16}$

1. Bienes conmemorativos. La Corte IDH en repetidas ocasiones ha dispuesto como medida de reparación dar el nombre de las víctimas a algún centro educativo, así como la construcción de monumentos y la elaboración de placas, con el propósito de conmemorar los hechos sucedidos y recordar a las víctimas.

2. Búsqueda de los restos mortales. Para la Corte IDH, especialmente en los casos de desaparición forzada de personas, la búsqueda de los restos mortales y la entrega de estos a sus familiares constituye un acto de reparación y justicia en sí mismo, porque conduce a dignificar a las víctimas y les permite a sus familiares darles una adecuada sepultura de acuerdo con sus creencias y costumbres.

3. Disculpa pública y reconocimiento de responsabilidad internacional. La Corte IDH ha establecido esta medida como una medida de satisfacción para las víctimas y como garantía de no repetición de las graves violaciones de derechos humanos que han ocurrido. En este sentido, ordena al Estado que reconozca públicamente, con presencia de altas autoridades, su responsabilidad internacional por los hechos del caso y que emita una disculpa a los familiares de las víctimas de violaciones a los derechos humanos. Esta disculpa pública es de gran valoración para la satisfacción moral de las víctimas o sus derechohabientes, así como por el servicio a la verdad en bien de los agraviados y de la sociedad en general.

4. Obligación del Estado de investigar los hechos del caso, identificar, juzgar y sancionar a los responsables. Como parte de esta medida, la Corte IDH ordena que los resultados de los procesos penales sean públicamente divulgados por el Estado a la sociedad, con el fin de que pueda conocer la verdad sobre los hechos ocurridos.

5. Publicación de las partes pertinentes de las sentencias. La Corte IDH, en la mayoría de casos, ha ordenado publicar apartes de las sentencias en el diario oficial. Para el caso de Colombia ha ordenado publicar en el Diario Oficial y en un diario de amplia circulación nacional.

16. Véase Juana Acosta y Diana Bravo. El cumplimiento de los fines de reparación integral de las medidas ordenadas por la Corte Interamericana de Derechos Humanos: énfasis en la experiencia colombiana. InTERnational LAW, Revista Colombiana DE Derecho Internacional 13. 2008. Págs. 333-335. 
6. Tratamiento médico y psicológico a las personas que asílo deseen. La Corte IDH ordena esta medida como una forma de reducir los padecimientos físicos y psicológicos de las víctimas. Asimismo, ordena que el Estado debe brindar esta atención médica y psicológica sin ningún cargo para los beneficiarios, y por el tiempo que sea necesario, incluida la provisión de medicamentos.

A manera enunciativa, resulta importante mencionar que la Corte IDH también ha ordenado otro tipo de medidas, tales como: la obligación de tomar medidas efectivas con el propósito de evitar la repetición de los hechos (derogación de leyes, expedición de normas, supresión de prácticas); la obligación de garantizar las condiciones de seguridad para el retorno de las personas desplazadas; el establecimiento de programas de educación en derechos humanos para funcionarios de la fuerza pública; el otorgamiento de becas estudiantiles; el diseño y la implementación de programas sociales; y la construcción de planes de vivienda.

El desarrollo de las medidas de satisfacción implica que se pueden adicionar aquellas que sean identificadas y señaladas por las respectivas comunidades étnicas, en el marco de los procesos de consulta que el gobierno colombiano debe adelantar ante ellos.

Las medidas de satisfacción incluyen, además del esclarecimiento de los hechos y la sanción a los responsables a fin de evitar su impunidad, las siguientes: ${ }^{17}$

1. Apoyo para la reconstrucción del movimiento y el tejido social de las víctimas, especialmente de las mujeres.

2. Construcción de monumentos públicos que enaltezcan a las víctimas, los cuales podrán ser diseñados por artistas pertenecientes a esas comunidades, a la luz de las tradiciones y la cultura del sujeto colectivo respectivo.

3. Creación y difusión de campañas para medios de comunicación sobre el valor de la diferencia cultural, y sobre la importancia de erradicar todas las manifestaciones de racismo y de respetar los derechos del pueblo victimizado. Estas campañas

17. Véase Hernán A. Olano. Trámite legal para el pago de obligaciones pecuniarias impuestas al Estado colombiano en decisiones sobre Derechos Humanos y Derecho Internacional Humanitario. Boletín Mexicano de Derecho Comparado 137. Mayo-agosto de 2013. Págs. 559-561. deben propender a que los ciudadanos entiendan el valor de la diferencia cultural y del pluralismo.

4. Difusión de campañas que muestren la no participación del pueblo victimizado en el conflicto armado.

5. Difusión en diarios de masiva circulación y en cadenas radiales de las decisiones judiciales que reivindiquen los derechos del pueblo víctima, con el fin de que toda la sociedad conozca esos contenidos.

6. Difusión pública y completa del relato de las víctimas sobre el hecho que las victimizó, siempre que no provoque más daños innecesarios ni genere peligros de seguridad, para lo cual se contará con la autorización de la víctima de que se trate. La difusión además de hacerse en castellano, deberá efectuarse en las lenguas y con las formas de expresión del pueblo víctima.

7. Efectuar las publicaciones y las acciones a que haya lugar relacionadas con el numeral anterior. Estas publicaciones deberán hacerse en el dialecto propio de las víctimas y en castellano.

8. Fortalecimiento de programas interculturales en materia de música a cargo del Ministerio de Cultura relacionados con la cultura de los pueblos victimizados.

9. Investigación, juzgamiento y sanción de los responsables de las violaciones de derechos humanos.

10. La adopción de medidas de reparación simbólica para preservar la memoria histórica, la aceptación pública de los crímenes por el victimario, la solicitud del perdón de los perpetradores y el restablecimiento de la dignidad de las víctimas.

11. La búsqueda de las personas desaparecidas, de las identidades de los niños secuestrados o reclutados forzosamente, y de los cadáveres de las personas asesinadas, así como la ayuda para recuperarlos, identificarlos y volver a inhumarlos según el deseo explícito de la víctima, su pueblo o las prácticas culturales de su pueblo y su familia.

12. La realización de una declaración oficial o la adopción de una decisión judicial que restablezca la dignidad, la reputación y los derechos de las víctimas, individuales o colectivas, y de las personas estrechamente vinculadas a ellas.

13. La verificación de los hechos y la revelación completa de la verdad, en la medida en que esa revelación no provoque más daños o amenace la seguridad y los intereses de las víctimas, individuales o colectivas, de sus familiares, de los testigos o de personas que han intervenido bien para 
ayudar a la víctima, o bien para impedir que se produzcan nuevas violaciones. La difusión, además de hacerse en castellano, deberá efectuarse en las lenguas y con las formas de expresión de las víctimas.

14. Realización de actos conmemorativos y homenajes públicos, en cuya planeación y puesta en marcha participarán las víctimas. Estos actos y homenajes deberán contar con componentes diferenciadores que resalten y enaltezcan la cultura y las tradiciones del pueblo víctima Rom, indígena o comunidad negra correspondientes.

15. Realización de reconocimientos públicos que deberán contar con la presencia del pueblo víctima y de la sociedad civil. En estos eventos se garantizará la traducción para que los miembros de los sujetos colectivos reciban este reconocimiento en su propia lengua.

16. Reconocimiento público de la responsabilidad de los autores de las violaciones de derechos humanos y difusión de las disculpas y aceptaciones de responsabilidad hechas por los victimarios.

17. Reconocimiento público del carácter de víctima, de su dignidad, nombre y honor, ante la comunidad y el ofensor.

Igualmente, salvo en caso de guerra exterior, las víctimas que estén obligadas a prestar el servicio militar quedan exentas de prestarlo, sin perjuicio de la obligación de inscribirse y adelantar los demás trámites correspondientes para resolver su situación militar por un lapso de cinco (5) años, contados a partir del 9 de diciembre de 2011 o de la ocurrencia del hecho victimizante. Las víctimas estarán exentas de cualquier pago de la cuota de compensación militar.

Ahora, el jefe de Estado quiere revivir normas inexequibles, pues por ejemplo, para la Corte Constitucional, la concentración de funciones en el Presidente de la República (encabezar el poder nacional y el sistema de seguridad y defensa, presidir el Consejo Superior de Seguridad y Defensa Nacional, el Consejo Nacional de Seguridad y Defensa y el Consejo Nacional de Movilización; así como ordenar y dirigir los planes de movilización y desmovilización nacional, y aprobar el plan de seguridad y defensa nacional, los documentos primarios sobre seguridad y defensa nacional, los planes de guerra presentados por el Consejo Superior de Seguridad y Defensa, y la estrategia de seguridad y defensa nacional), resultaba problemática. Esto en razón a que el sistema de seguridad y defensa, según la definición del artículo 3 de la Ley 684 de 2001, ${ }^{18}$ comprendía todo el Estado, lo cual para la Corte creaba un suprapoder, como ya se dijo, al punto de que el mismo presidente podía definir los llamados objetivos nacionales. ${ }^{19}$ A fin de alcanzar estos objetivos, se obtiene la facultad de subordinar a las otras ramas del poder, lo cual choca frontalmente, al menos, con los siguientes principios constitucionales básicos y, bajo la ilusión de la paz, abre el camino para un Estado totalitario:

- La separación de poderes, que amenaza también los derechos de las personas.

- El principio democrático, ya que los objetivos nacionales se definían exclusivamente por el Presidente de la República, sin "someterlos al foro por excelencia de la deliberación democrática, que es el Congreso", y al escrutinio de la ciudadanía, con lo se desconocen los artículos $114,{ }^{20} 189$ ord. 4 y 135 de la Carta.

- La supremacía del poder civil sobre el mando militar, que para la Corte erosionaba el carácter no deliberante de la Fuerza Pública, ya que al elaborar el Ministerio de Defensa en coordinación con los altos mandos militares y el director de la Policía los documentos primarios y secundarios, que contendrían los objetivos del sistema de seguridad y defensa, así como los distintos planes y programas para alcanzar esas metas, se estaría, según la Ley 684 de 2001, “deliberando permanentemente sobre los desafíos que tiene Colombia en los campos políticos, económicos y sociales, y diseñen estrategias y planes para enfrentar esos retos".

Todas estas disposiciones, así como los términos definidos y utilizados en este artículo de revisión, están basados en la dignidad humana, la Constitución Política Nacional, los instrumentos internacionales que forman parte del bloque de constitucionalidad, las leyes, la jurisprudencia y los principios

\footnotetext{
18. Ley 684 de 2001. Por la cual se expiden normas sobre la organización y funcionamiento de la seguridad y defensa nacional y se dictan otras disposiciones. Agosto 18 de 2001. Do N. ${ }^{\circ} 44.522$. 19. Los Objetivos Nacionales se definen así: "Serán los definidos por el Presidente de la República teniendo en cuenta que como supremo deber y misión constitucional le corresponde diseñar y establecer los medios y mecanismos para hacer una Nación más segura y más próspera, particularmente en tres ámbitos: seguridad con efectiva diplomacia y con fuerzas militares listas para luchar y ganar, impulsar la prosperidad de la economía y promoción de la democracia”. Id. Artículo 41.

20. Entendiéndose del artículo el aparte sobre el control político.
} 
internacionales a la verdad, a la justicia, a la reparación y a las garantías de no repetición. Respetan la cultura, la existencia material e incluyen los derechos de las víctimas de violaciones graves y manifiestas de normas internacionales de derechos humanos o infracciones al Derecho Internacional Humanitario, así como buscan dignificar al pueblo por medio de sus derechos individuales y colectivos, siempre que hayan sido víctimas por hechos ocurridos antes del 1 de enero de 1985, con el consecuente derecho a la verdad, a medidas de reparación simbólica y a las garantías de no repetición previstas en la Ley 1448 y sus decretos reglamentarios, así como en la Ley 288 , como parte que son del conglomerado social.

Uno de los aspectos que más incrementa el deterioro de los derechos humanos es la debilidad institucional del Estado para asumir la protección integral de los derechos humanos y cumplir con el cometido que la Constitución Política impone a las autoridades con el propósito de proteger a los habitantes de la República en su vida, honra, bienes, creencias y demás derechos y libertades, pero también la Constitución Política impone a los particulares conocer la Carta y las leyes. Sin compromiso ciudadano, los términos aquí expuestos no serán conocidos por los habitantes del Estado y su ignorancia, de acuerdo con el aforismo del Derecho romano, no servirá de excusa para firmar un compromiso por la paz.

En el siglo $\mathrm{xx}$, las cosas no se apartaron de la tradición. La intensidad de los enfrentamientos comienza muy temprano con la Guerra de los Mil Días, un evento violento de alta intensidad que se desarrolló entre 1899 y 1902, el cual dejó un saldo de 80000 muertos y culminó con un "Tratado de Paz" firmado a bordo del buque Almirante Wisconsin de la Armada de Estados Unidos de América.

Esta guerra afectó todo el país y además de las batallas estuvo unida a una insurrección generalizada en un número considerable de municipios, en los cuales se formaron bandas o grupos de guerrilleros que alternaron el robo y el saqueo con la defensa de su partido, en especial el partido liberal. ${ }^{21}$

Luego de una relativa tregua entre 1910 y 1945, en la que, sin embargo, murió un estudiante durante el gobierno de Abadía Méndez, se produjo una

21. Deas Malcom. Del poder y la gramática. Y otros ensayos SObRe historia, POLÍtica y Literatura COLOMbianas. Tercer Mundo Editores. (1995). Pág. 201 insurrección comunista en El Líbano en 1929, con repercusiones en La Palma, Topaipí, Yacopí, Puerto Wilches y San Vicente de Chucurí. También se registró el asesinato de ocho conservadores en Gachetá durante las elecciones de 1938, lo cual evidencia cómo la política colombiana estuvo marcada por la violencia,

[...] bajo las formas del conservatismo tradicional, agrario y católico de un lado y del liberalismo modernizante, urbano y anticlerical del otro. El fervor de estas pasiones dejó más de 200.000 muertos en los enfrentamientos de mediados de siglo conocidos como "La Violencia".22

Ignominioso periodo en el cual se manifestó un comportamiento colectivo generalizado que comenzó en 1946 y cubrió todo el territorio nacional, e hizo pensar que la nacionalidad colombiana estaba asociada con la barbarie, particularmente por la acción de bandoleros con nombres bien curiosos: Teniente Gorila, Malasombra, Malasangre, El Cóndor, Pielroja, El Vampiro, Avenegra, Sangrenegra, El Terror del Llano y otros, quienes generalmente practicaban el "corte corbata", en el cual "la lengua quedaba colgando desde el pescuezo". ${ }^{23}$

"La Violencia" terminó, curiosamente, por medio de un decreto, el 1853 de 1954, el cual incluyó una amnistía total ordenada por el gobierno militar del general Gustavo Rojas Pinilla, en los siguientes términos:

Concédase amnistía para los delitos políticos cometidos con anterioridad al 1 de enero del presente año. Para los efectos del presente decreto, se entiende por delitos políticos todos aquellos cometidos por nacionales colombianos cuyo móvil haya sido el ataque al Gobierno, o que puedan explicarse por extralimitación en el apoyo o adhesión a este, o por aversión o sectarismos políticos. ${ }^{24}$

No se extendieron los beneficios de esta norma a los "delitos cuyos caracteres de atrocidad revelen una extrema insensibilidad moral”, según Gaitán Mahecha, asignándose a los jueces y magistrados

22. Véase Boaventura de Sousa Santos y Mauricio García Villegas. El Caleidoscopio de las justicias en Colombia. Siglo del Hombre Editores y Universidad de los Andes. (2001). Pág. 155.

23. Véase Eduardo Galeano. LAS venas abiertas de América Latina. Siglo xxi Editores. (2012). Pág. 57.

24. Véase Gaitán Mahecha. (2015). Pág. 6. 
estudiar la posibilidad de aplicación de medidas de amnistía e indulto.

Alberto Lleras Camargo y, más adelante, Julio César Turbay Ayala concedieron amnistías condicionadas que implicaban la dejación de las armas, aunque no tuvieron efecto alguno para conseguir la paz definitiva en Colombia.

Turbay creó en 1981 una Comisión de Paz, frente a la cual puso al expresidente Carlos Lleras Restrepo. Durante este gobierno de Turbay se combatió el auge de los grupos insurgentes, frente a lo cual creó un instrumento jurídico especial, el famoso "Estatuto de Seguridad", el cual concedía a los militares facultades judiciales y dio vía libre a la Fuerza Pública para contener la avanzada guerrillera, a costa de algunos desmanes condenados posteriormente por el Consejo de Estado. En este cuatrienio, el M-19 sustrajo 5000 armas de las bodegas del Cantón Norte de Bogotá y, entre otros actos, llevó a cabo la toma en Bogotá de la Embajada de República Dominicana, que implicó el secuestro de catorce embajadores, incluido el nuncio apostólico de Su Santidad Juan Pablo II.

Las elecciones de 1982 -que fueron muy reñidas- llevaron al poder al presidente Belisario Betancur, quien desde el primer día "hizo de los diálogos con las guerrillas la columna vertebral de su Gobierno". ${ }^{25}$ Después, promulgó la Ley 35 de 1982, la cual dispuso conceder amnistía general a los autores, cómplices o encubridores de hechos constitutivos de delitos políticos cometidos antes de la vigencia de esa disposición legal, y definió como delitos políticos los de rebelión, sedición y asonada, así como los conexos con ellos, por haber sido cometidos para facilitarlos, procurarlos, consumarlos u ocultarlos. Sin embargo, en el artículo 3 se disponía que "los homicidios fuera de combate no quedarán amparados por la amnistía, si fueron cometidos con sevicia o colocando a la víctima en situación de indefensión o inferioridad, o aprovechándose de esa situación". ${ }^{26}$

Belisario constituyó también en 1982 una Comisión de Paz, integrada por representantes de todas las tendencias, incluso del Partido Comunista, convocando para septiembre de 1982 una cumbre política, la cual llevó a que el Congreso de la República aprobara el 19 de noviembre de 1982 una

25. Véase Rafael Pardo Rueda. La historia de las guerras. De Bolsillo. (2010). Pág. 734

26. Véase Ley 35 de 1982. Por la cual se decreta una amnistía y se dictan normas tendientes al restablecimiento y preservación de la paz. Noviembre 19 de 1982 . Do N. ${ }^{\circ} 36.133$ bis. ley de amnistía incondicional, en un plano totalmente opuesto a lo que había sido la política de contención y hasta de represión que se vivió durante el gobierno del presidente Julio César Turbay Ayala.

Para el 30 de enero de 1983, se llevaría a cabo una reunión entre los integrantes de la Comisión de Paz y el Secretariado de las Fuerzas Armadas Revolucionarias de Colombia (FARC), manifestándose estas en los siguientes términos:

La resolución del presidente Belisario Betancur de crear las condiciones de una amnistía que consolide y prolongue en el tiempo la paz entre los colombianos (...) Debemos celebrar la propuesta de que se establezca el marco de una nueva coexistencia y de la paz política nacional, con participación de todos los partidos y de las fuerzas progresistas del país. ${ }^{27}$

Poco tiempo después, el M-19 hizo saber que reanudaba sus combates y las FARC se extendieron por otras zonas, haciendo fracasar la política de reinserción y amnistía al cambiarse por lo que el líder del M-19, Jaime Bateman Cayón, denominó una "tregua provisional", basada en lo que realmente quería el pueblo, esto es "salarios justos, una administración pública eficaz y al alcance del pueblo, la salud y la educación para todos". ${ }^{28}$

Para la guerrilla:

Los años de Betancur fueron de resultado mixto. Ganaron en lo político como nunca antes, alcanzaron los más grandes escenarios de visibilidad nacional e internacional, pero mostraron también su incapacidad política, su falta de propuestas, su desconexión con el país y cayeron, al final del proceso, en un profundo desprestigio. $^{29}$

Posteriormente, la Comisión de Estudios Sobre la Violencia, creada por el presidente Virgilio Barco e integrada por los denominados "violentólogos" (científicos de la violencia), identificó diez tipos importantes de violencia en Colombia:

1. La de ciudadanos particulares no organizados.

2. La de ciudadanos particulares organizados.

3. La de grupos armados contra ciudadanos particulares.
27. Véase Daniel Pécaut. Entre el conflicto armado y otras guerras internas contemporáneas. CRÓNICA DE CUATRO DÉCADAS DE POLÍtica Colombiana. Editorial Norma. (2006). Pág. 321.

28. Id., Pág. 322.

29. Véase R. Pardo Rueda, supra, nota 25. Pág. 737. 
4. La de la guerrilla contra el Estado.

5. La de la vida privada de los ciudadanos.

6. La del crimen organizado contra ciudadanos particulares.

7. La estatal contra las minorías étnicas.

8. La estatal contra los movimientos sociales de protesta.

9. La generada por el crimen organizado contra políticos y periodistas.

10. La generada por el Estado como resultado de sus esfuerzos por preservar la ley y el orden.

Barco, que inició su administración con el lema "Mano tendida y pulso firme", fue quien promulgó la Ley 77 de 1989, la cual dejó jurídicamente en el olvido la sangrienta toma del Palacio de Justicia en 1985, ya que en esta ley se indultó a quienes gestaron, urdieron o consumaron este acto de violencia contra las más altas corporaciones por entonces existentes del poder judicial: la Corte Suprema de Justicia y el Consejo de Estado. Cualesquiera integrantes de organizaciones al margen de la ley que inequívocamente demostraran su voluntad de reincorporarse a la vida civil pudieron ejercer ese beneficio.

Durante el gobierno Barco se mantuvieron acuerdos con las FARC, pero ellas rompieron en varias ocasiones la tregua e intensificaron la técnica de los secuestros como presión política y económica.

En 1988, Barco retomó los acercamientos de paz. Sin embargo, las ejecuciones masivas de los miembros de la Unión Patriótica impidieron el avance de las negociaciones, lo mismo que varios ataques guerrilleros que dejaron decenas de muertos.

La paz que reclama el ciudadano cada vez se ve más disminuida por el incremento desmedido de la acción del terrorismo, la subversión, la guerrilla y la delincuencia común, todos los cuales están movidos además por oscuros intereses económicos. Con sus prácticas al margen de la ley, la subversión y los distintos grupos han minado cada día la seguridad y la tranquilidad ciudadana, y han hecho que esa paz se vaya convirtiendo en una utopía y un sueño lejano de alcanzar.

Las repercusiones que los problemas de orden público tengan en las relaciones internacionales del país también preocupan a la nación. Sin embargo, el Estado cuenta con elementos a la mano para que cada ciudadano renuncie al uso de la fuerza y se puedan crear las garantías del aparato de justicia como principio básico para que siempre se dé la igualdad de condiciones, nunca impere la ley del más fuerte y se respeten los derechos humanos fundamentales de los habitantes.
Por esa razón, la Corte Constitucional, en Sentencia C-283, ha expresado:

La paz no es algo que concierna privativamente a los organismos y funcionarios del Estado, sino que, por el contrario, atañe a todos los colombianos, como lo declara el artículo 22 de la Constitución, a cuyo tenor es un derecho de todos y un deber de obligatorio cumplimiento. Menos todavía puede sostenerse que esté circunscrito a la actividad y decisión de una sola rama del Poder Público. ${ }^{30}$

De todas maneras, es notoria la preocupación y el temor en la sociedad por la impunidad, por el respeto a los derechos humanos y el Derecho Internacional Humanitario, así como por la necesidad de fortalecer las instituciones en diferentes zonas del país, lo cual no sería viable sin la colaboración plena de las administraciones municipales elegidas por el pueblo para cumplir esa misión.

Esta noción constituye el presupuesto básico de la Constitución democrática, que ampara la vigencia de un orden justo. Sin embargo, si no se cuenta con los particulares para suplir las deficiencias del Estado, poco o nada podrá hacer este para que funcione el engranaje que lo mueve.

Si bien la sociedad civil debe mantenerse al margen de la lucha entre las diversas organizaciones delictivas y las autoridades de la República, el fallo C-572 de 1997 de la Corte Constitucional fue claro cuando desarrolló su concepto de la siguiente manera:

En primer lugar, la sociedad civil está inmersa en el conflicto, porque ella (es decir, todos sus miembros) es la víctima de quienes actúan por fuera de la ley, empleando la fuerza contra el derecho... Por esto es inaceptable la tesis de que los delincuentes combaten contra las autoridades legítimas respetando la vida, la libertad y los bienes de los particulares: no, éstos son sus víctimas, precisamente porque están indefensos y carecen de organizaciones de vigilancia y seguridad que los protejan, o ellas son insuficientes. ${ }^{31}$

Merece mención el hecho de que:

Si bien la guerra en Colombia sigue siendo un conflicto interno, hoy la agenda internacional abarca aspectos como el medio ambiente, el narcotráfico, las

30. Véase Corte Constitucional de Colombia. Sentencia C-283/95. (M.P. José Gregorio Hernández; Junio 25 de 1995).

31. Corte Constitucional de Colombia, supra, nota 13. 
migraciones, la democracia y, con una gran relevancia, los derechos humanos, todos ellos temas centrales de la agenda nacional y ligados estrechamente a la confrontación armada. ${ }^{32}$

No obstante, tan irreal sería desconocer los problemas como pasar por alto los cambios. "Tan ingenuo es esperar que la Constitución transforme todo para reclamarle que todavía haya pobrezas, angustias y sangre”, decía el expresidente César Gaviria en el primer aniversario de la Constitución Política de Colombia. Sin duda, no se podría continuar con la defensa de las instituciones sin la colaboración de los municipios y de los ciudadanos particulares que de ellos forman parte y, mucho más, sin la posibilidad de defensa de los derechos humanos de los colombianos, que antes con más propiedad se denominaban derechos fundamentales o esenciales de las personas, a fin de distinguirlos de otros derechos no esenciales. Sin embargo, es claro que también son humanos, como la defensa de la vida y de los bienes de las personas por medio de instituciones destinadas exclusivamente a proveer seguridad en áreas de alto riesgo o de interés público, con miras a prevenir o detener perturbaciones a la seguridad y a la tranquilidad individuales.

La apuesta de Juan Manuel Santos por la paz lo llevó en agosto de 2012 a dirigirse a la nación y anunciar el inicio de los diálogos con las farc en La Habana, Cuba. Previamente, el Congreso de la República había emitido el Acto Legislativo 1 de 2012, ${ }^{33}$ creándose allí este sistema jurídico que, entre otras cosas, ordena que sus elementos estén destinados a la terminación del conflicto armado, para lo cual fue necesaria la expedición de una ley estatutaria que reguló los instrumentos de carácter judicial y extrajudicial, a fin de garantizar los "deberes estatales de investigación y sanción" de los delitos cometidos durante el conflicto armado.

Reunidos primero en Oslo, Noruega, los voceros del Gobierno de Colombia y los de las Fuerzas Armadas Revolucionarias de Colombia - Ejército del Pueblo (FARC - EP) acordaron la instalación pública de la mesa de conversaciones encargada de desarrollar el acuerdo general para la terminación del conflicto y la construcción de una paz estable y duradera. De este modo, se inició formalmente la segunda fase de los diálogos de paz, los cuales comenzaron el 15 de noviembre de 2012 en Cuba.

\footnotetext{
32. Véase Construir la paz del mañana. Pág. 6. s. f., s. p. i. 33. Véase Acto Legislativo 1 de 2012. [Congreso de la República]. Por medio del cual se establecen instrumentos jurídicos de justicia transicional en el marco del artículo 22 de la Constitución Política y se dictan otras disposiciones. Julio 31 de 2012. Do N. ${ }^{\circ} 48.508$.
}

El 26 de mayo de 2013, se lograron los primeros acuerdos sobre los siguientes temas:

- Acceso y uso de la tierra, tierras improductivas, formalización de la propiedad, frontera agrícola y protección de zonas de reserva.

- Desarrollo social: salud, educación, vivienda, erradicación de la pobreza.

- Estímulo a la producción agropecuaria y a la economía solidaria y cooperativa. Asistencia técnica, subsidios, créditos, generación de ingresos, mercadeo y formalización laboral.

- Infraestructura y adecuación de tierras.

- Políticas alimentarias y nutricionales.

- Programas de desarrollo con enfoque territorial.

Durante el desarrollo de estos puntos del acuerdo general, avanzaron en la redacción de distintos mecanismos de participación ciudadana y diálogo social, y continuaron la discusión de las distintas concepciones sobre la mejor forma de fortalecer las organizaciones y los movimientos sociales, así como las garantías necesarias para su efectivo funcionamiento dentro del marco de la democracia.

Así mismo, se acordó establecer medidas para garantizar y promover una cultura de reconciliación, convivencia, tolerancia y no estigmatización, lo cual implica un lenguaje y un comportamiento de respeto por las ideas, tanto de los opositores políticos, como de las organizaciones sociales y de derechos humanos.

El 16 de mayo de 2014, se logró un acuerdo sobre los tres subpuntos del punto 4 del acuerdo general:

1. Programas de sustitución de cultivos de uso ilícito. Planes integrales de desarrollo con participación de las comunidades en el diseño, la ejecución y la evaluación de los programas de sustitución y recuperación ambiental de las áreas afectadas por dichos cultivos.

2. Programas de prevención del consumo y la salud pública.

3. Solución al fenómeno de producción y comercialización de narcóticos.

Así las cosas, las partes firmaron unos compromisos. El 5 de junio de 2014, el tema abordado dentro de la agenda fue el de las víctimas del conflicto.

Convencidos de que la satisfacción de los derechos de las víctimas forma parte fundamental de las garantías para la conquista de la paz, y que la terminación del conflicto contribuirá decididamente a la satisfacción de esos derechos, declaran que la discusión del punto 5 estará enmarcada en los siguientes principios: 
1. El reconocimiento de las víctimas. Es necesario reconocer a todas las víctimas del conflicto, no solo en su condición de víctimas, sino también y, principalmente, en su condición de ciudadanos con derechos.

2. El reconocimiento de responsabilidad. Cualquier discusión de este punto debe partir del reconocimiento de responsabilidad frente a las víctimas del conflicto. No vamos a intercambiar impunidades.

3. Satisfacción de los derechos de las víctimas. Los derechos de las víctimas del conflicto no son negociables. Se trata de ponerse de acuerdo acerca de cómo deberán ser satisfechos de la mejor manera en el marco del fin del conflicto.

4. Laparticipación de las víctimas. La discusión sobre la satisfacción de los derechos de las víctimas de graves violaciones de derechos humanos e infracciones al Derecho Internacional Humanitario con ocasión del conflicto requiere necesariamente de la participación de las víctimas, por diferentes medios y en diferentes momentos.

5. El esclarecimiento de la verdad. Esclarecer lo sucedido a lo largo del conflicto, incluyendo sus múltiples causas, orígenes y sus efectos, es parte fundamental de la satisfacción de los derechos de las víctimas y de la sociedad en general. La reconstrucción de la confianza depende del esclarecimiento pleno y del reconocimiento de la verdad.

6. La reparación de las víctimas. Las víctimas tienen derecho a ser resarcidas por los daños que sufrieron a causa del conflicto. Restablecer los derechos de las víctimas y transformar sus condiciones de vida en el marco del fin del conflicto es parte fundamental de la construcción de una paz estable y duradera.

7. Las garantías de protección y seguridad. Proteger la vida y la integridad personal de las víctimas es el primer paso para la satisfacción de sus demás derechos.

8. La garantía de no repetición. El fin del conflicto y la implementación de las reformas que surjan del acuerdo final constituyen la principal garantía de no repetición y la forma de asegurar que no surjan nuevas generaciones de víctimas. Las medidas que se adopten tanto en el punto 5, como en los demás puntos de la agenda deben apuntar a garantizar la no repetición, de manera que ningún colombiano vuelva a ser puesto en condición de víctima o en riesgo de serlo.

9. Principio de reconciliación. Uno de los objetivos de la satisfacción de los derechos de las víctimas es la reconciliación de toda la ciudadanía colombiana para transitar caminos de civilidad y convivencia.
10. Enfoque de derechos. Todos los acuerdos a los que lleguemos sobre los puntos de la agenda, y en particular sobre el punto 5 "Víctimas", deben contribuir a la protección y la garantía del goce efectivo de los derechos de todos y todas. Los derechos humanos son inherentes a todos los seres humanos por igual, lo que significa que les pertenecen por el hecho de serlo y en consecuencia su reconocimiento no es una concesión; son universales, indivisibles e interdependientes, y deben ser considerados en forma global y de manera justa y equitativa. Por consiguiente, el Estado tiene el deber de promover y proteger todos los derechos y las libertades fundamentales, y todos los ciudadanos tienen el deber de no violar los derechos humanos de sus conciudadanos. Atendiendo los principios de universalidad, igualdad y progresividad, y para efectos de resarcimiento, se tendrán en cuentan las vulneraciones que en razón al conflicto hubieran tenido los derechos económicos, sociales y culturales.

Adicionalmente, se comenzaron a recibir grupos de víctimas para ser escuchadas dentro de los periodos de diálogo en La Habana, junto con los más de 3000 testimonios y propuestas recogidos en los foros sobre víctimas a lo largo y ancho del país.

Las delegaciones acordaron establecer un mecanismo permanente por medio de los países garantes, con el fin de facilitar la solución de eventuales crisis que se pudieran presentar en el futuro, de manera que se comenzó a hablar de "desescalamiento" del conflicto, vocablo que coloquialmente comenzaron a utilizar el presidente Juan Manuel Santos Calderón, y los negociadores del Gobierno colombiano y de la guerrilla de las FARC en los diálogos de La Habana.

Este nombre de acción se deriva de desescalar, término registrado en el Diccionario del verbo español, hispanoamericano y dialectal, de Jaime Suances-Torres, y en el Diccionario del español actual. Este último lo define así: "Disminuir la extensión, intensidad o magnitud (de algo, esp. de la lucha o la violencia)".

No obstante, el Manual de español urgente, de la Fundeú (Fundación del Español Urgente), desestima este vocablo: "Desescalar. Rechácese este verbo. Dígase reducir, atenuar, distender".

Por otro lado, el sustantivo desescalamiento, que también se documenta en los bancos de datos de la Real Academia Española, tiene como sinónimo la palabra desescalada. Esta última aparece en el citado Diccionario del español actual: "Disminución en la extensión, intensidad o magnitud (de algo, esp. de la lucha o la violencia)". 
Asimismo, desescalada consta en el Gran diccionario de la lengua española con este significado: "Disminución progresiva del peligro y la tensión resultantes de un proceso de escalada: la intervención de la onu dio lugar a la desescalada del conflicto bélico".

Conclusión: Tanto desescalar como desescalamiento (o desescalada) son voces morfológicamente correctas y necesarias, razón por la que son válidas. ${ }^{34}$

Aunque se habla de perdón, no podemos desconocer que Karl Jaspers, ${ }^{35}$ al escribir luego de la Segunda Guerra Mundial sobre la culpa del pueblo alemán, hablaba de cuatro categorías de culpa:

a. La culpa criminal como consecuencia de los crímenes que se cometen en violación a los estatutos legales correspondientes y cuya instancia son los jueces.

b. La culpa política como resultado de las acciones de los gobernantes y de los ciudadanos, y cuya instancia es la fuerza y la voluntad del vencedor.

c. La culpa moral que nace de los actos de cada individuo y cuya instancia es la conciencia de cada cual.

d. Y la culpa metafísica, corolario del principio de solidaridad universal, que nos hace a todos responsables de todas las injusticias y en virtud de la cual deberemos todos comparecer ante Dios.

La importancia de esta clasificación radica en que frente a las distintas categorías de culpa se debe construir el perdón, el cual libera a las víctimas y libera también un sentimiento de arrepentimiento por parte de los agresores, superando lo imperdonable hacia ellos. De lo contrario, dice Polo, "seguiremos asesinando a los perdonados y seguirán siendo incumplidas las promesas (...) De tal manera que, en la búsqueda de la solución del conflicto y en la construcción de esta nueva cultura, nadie puede ser indiferente, todos somos co-responsables". ${ }^{36}$

\section{ConClusiones}

Algo para tener muy presente, así como para concluir las apreciaciones desarrolladas en esta reflexión, es

34. Respuesta a la consulta solicitada por el suscrito a la Academia Colombiana de la Lengua, a fin de lograr mayor precisión conceptual del término utilizado por el jefe de Estado.

35. Citado en Joaquín Polo. Perdón y posconflicto. Memorias DE LAS VIII JoRnadas de ACTUalización Filosófica. Universidad de La Sabana. (2002). Págs. 239-258

36. Id. Págs. 256-257. que Colombia incluyó en su Constitución el contenido del Tratado de Roma de 1988, el cual forma parte del bloque de constitucionalidad. Sin embargo, no obstante ser tenido como válido por la Corte Constitucional, es necesario advertir que no porque este tratado esté vigente por medio de la Ley 742 de 2002, y a él se haya adherido Colombia, tendría aplicación, ya que la competencia de la Corte Penal Internacional, según el párrafo 10 del preámbulo del Estatuto de Roma y su artículo 1, es meramente "complementaria de las jurisdicciones penales nacionales" ${ }^{37}$ Esto significa que el Tratado de Roma no ha reemplazado la jurisdicción penal ordinaria ni la justicia transicional y que, como paso firme hacia la paz, los acuerdos deberían incluir que las investigaciones o los enjuiciamientos se realicen en conformidad con el Derecho nacional y los derechos constitucionales fundamentales por él protegidos $y$, muy excepcionalmente, en forma "complementaria" ante la Corte Penal Internacional, siempre y cuando no se pueda hacer en Colombia la investigación o el enjuiciamiento, ni se sustraiga a los implicados de las responsabilidades pertinentes.

Se debe tener en cuenta en esta conclusión que la Corte Constitucional, mediante Sentencia C-578 de 2002, ha expresado que las amnistías dictadas con el fin de consolidar la paz son un instrumento compatible con el debido respeto del Derecho Internacional Humanitario, y concluye:

Por lo anterior, sin adelantar juicio alguno sobre eventuales leyes de amnistía o indulto, no encuentra la Corte que la ratificación del Estatuto de Roma pueda implicar un obstáculo para futuros procesos de paz y de reconciliación nacional en donde se consideren medidas como los indultos y las amnistías con sujeción a los parámetros establecidos en la constitución y en los principios y normas del Derecho internacional aceptados por Colombia. ${ }^{38}$

Luchar y perdonar para que el amor sepa ahogar las ofensas. Se avecina en el proceso de paz un periodo de reconciliación. ¿Podrá poner la sociedad en práctica estas enseñanzas? Lo importante ante los naufragios es saber llegar a puerto. Aunque por más de sesenta años los colombianos han estado marcados por la violencia generalizada, las fórmulas de transición hacia la paz ya han sido dadas por la historia.

37. Corte Penal Internacional. Estatuto de Roma. (1998). Art. 1. 38. Véase Corte Constitucional de Colombia. Sentencia C-578/02. (M.P. José Cepeda Espinosa; Julio 30 de 2002). 
Ahora, lo importante es pensar en unas políticas públicas para el posacuerdo, las cuales incluyan la restitución a las víctimas, una pedagogía para la paz, la difusión de los puntos clave de la negociación y la recuperación del país en términos de perdón y reconciliación.

\section{REFERENCIAS}

Acto Legislativo 1 de 2012. [Congreso de la República]. Por medio del cual se establecen instrumentos jurídicos de justicia transicional en el marco del artículo 22 de la Constitución Política y se dictan otras disposiciones. Julio 31 de 2012. Do N. ${ }^{\circ} 48.508$.

Boaventura de Sousa Santos y Mauricio García Villegas. EL CAleidoscopio de las Justicias en Colombia. Siglo del Hombre Editores y Universidad de los Andes. (2001).

Carlos Alberto Olano Valderrama y Hernán Alejandro Olano García. Derecho constitucional general e instituciones políticas - Estado Social de Derecho. 3. a ed. Ediciones Librería del Profesional (2000).

Constitución Política de Colombia [Const]. Julio 7 de 1991 (Colombia).

Construir la paZ Del maÑana. s. f., s. p. i.

Corte Constitucional de Colombia. Sentencia T-102/93. (M.P. Carlos Gaviria Díaz; Marzo 10 de 1993).

Corte Constitucional de Colombia. Sentencia C-283/95. (M.P. José Gregorio Hernández; Junio 25 de 1995).

Corte Constitucional de Colombia. Sentencia C-328/96. (м.P. Eduardo Cifuentes Muñoz; Julio 25 de 1996).

Corte Constitucional de Colombia. Sentencia C-572/97. (м.P. Jorge Arango Mejía y Alejandro Martínez Caballero; Noviembre 7 de 1997).

Corte Constitucional de Colombia. Sentencia C-578/02. (M.P. José Cepeda Espinosa; Julio 30 de 2002).

Corte Penal Internacional. Estatuto de Roma. (1998).

Daniel Pécaut. Entre el conflicto armado y otras guerras internas contemporáneas. CRÓNICA DE CUATRO DÉCADAS DE POLÍ́ticA COLOMBIANA. Editorial Norma. (2006).
Deas Malcom. Del poder y la Gramática. Y otros ensaYOS SOBRE HISTORIA, POLÍTICA Y LITERATURA COLOMBIANAS. Tercer Mundo Editores. (1995).

Eduardo Galeano. Las venas abiertas de América LatiNA. Siglo XXI Editores. (2012).

Herbert Braun. Mataron a Gaitán. Vida pública y violencia urbana en Colombia. Alfaguara. (2013).

Hernán A. Olano. Constitución Política de Colombia. Doctrina y Ley. (2002).

Hernán A. Olano. Trámite legal para el pago de obligaciones pecuniarias impuestas al Estado colombiano en decisiones sobre Derechos Humanos y Derecho Internacional Humanitario. Boletín Mexicano de Derecho ComPARADO 137. Mayo-agosto de 2013. Págs. 559-561.

Joaquín Polo. Perdón y posconflicto. Memorias de las VIII JoRnadas de ACtualización Filosófica. Universidad de La Sabana. (2002). Págs. 239-258.

John K. Galbraith. LA ERA DE LA Incertidumbre. Universidad de Brasilia. (1979).

Juana Acosta y Diana Bravo. El cumplimiento de los fines de reparación integral de las medidas ordenadas por la Corte Interamericana de Derechos Humanos: énfasis en la experiencia colombiana. International LaW, Revista Colombiana de Derecho Internacional 13. 2008. Págs. 333-335.

Ley 35 de 1982. Por la cual se decreta una amnistía y se dictan normas tendientes al restablecimiento y preservación de la paz. Noviembre 19 de 1982. Do N. ${ }^{\circ} 36.133$ bis.

Ley 684 de 2001. Por la cual se expiden normas sobre la organización y funcionamiento de la seguridad y defensa nacional y se dictan otras disposiciones. Agosto $18 \mathrm{de}$ 2001. Do N. ${ }^{\circ} 44.522$

Ley 1448 de 2011. Por la cual se dictan medidas de atención, asistencia y reparación integral a las víctimas del conflicto armado interno y se dictan otras disposiciones. Junio 10 de 2011. Do N. ${ }^{\circ} 48096$

Manuel J. Cepeda. Los Derechos constitucionales, FUENTES INTERNACIONALES PARA SU INTERPRETACIÓn. Presidencia de la República de Colombia. (1994).

Rafael Pardo Rueda. La historia de las GUERRAs. De Bolsillo. (2010).

Vladimiro Naranjo. Elementos de Teoría ConstitucioNal E Instituciones Políticas. Temis. (1997). 